\section{BRUSHING ALL OF THE TEETH SIMULTANEOUSLY}

Y-Brush has been billed as the 'next generation electric toothbrush' that is able to brush all surfaces of the teeth efficiently in only ten seconds.

The Y-Brush was developed in France in close collaboration with dentists, and required almost four years of research and development.

Y-Brush is the only product on the market to use nylon bristles rather than silicone strips. A handle conveys vibrations to a nylon bristle brush which in turn moves in such a way to efficiently clean the teeth, gums and gum line. The vibrations provided by the device are based on specific sonic frequencies. Unlike silicone strips and other materials, nylon bristles are fine enough to reach in between the teeth, producing a deep clean and careful elimination of dental plaque.

As dentists are well aware, many patients find teeth brushing to be a strenuous and tedious chore, and numerous case studies show that brushing of the teeth is often done incorrectly.

As teeth should be brushed for two to three minutes, twice a day, this corresponds to a minimum of four seconds spent on one tooth.

The Y-Brush device brushes all of the top teeth simultaneously for five seconds, and then the bottom teeth for five seconds. The brush is in the shape of a ' $\mathrm{Y}$ ' allowing for complete coverage of all of the teeth.

The device was developed in such a way as to not be too bulky in the mouth, to not cause gag reflexes or tongue restriction during use. Different versions are available for children, teenagers and adults. It is also possible to use the device hands-free, simplifying the task for children and the elderly.

Y-Brush simplifies teeth brushing for everyone, including the young, elderly and individuals with reduced autonomy.

For more information about the Y-Brush, visit https://www.ybrush.com, where the device is also exclusively available.

\section{MAINTAIN EXCEPTIONAL HYGIENE STANDARDS}

Nuview is committed to helping dental practices maintain exceptional hygiene standards in accordance with HTM 01-05. That's why it manufactures and distributes its own Continu range of cleaning and disinfectant products. These alcohol-free, water-based solutions offer effective, long-lasting protection against a wide range of harmful microorganisms.

Always striving to provide helpful advice and guidance, Nuview also offers additional support in the form of team training and regular swab testing, to help clinicians optimise their infection control procedures.

Contact Nuview to find out how the friendly team could help you achieve high levels of compliance in practice.

For more information please call

Nuview on 01453 872266, email info@ nuview-ltd.com, visit www.nuview.co or 'like' Nuview on Facebook.

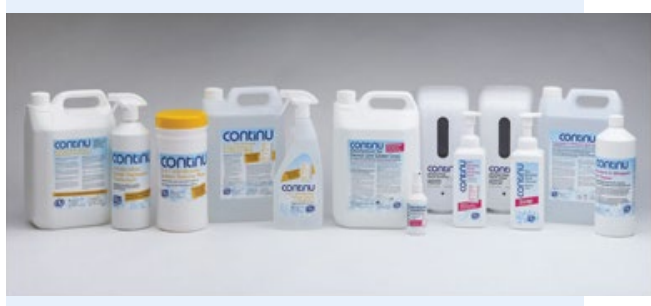

\title{
ECO-FRIENDLY MOUTHWASHES LAUNCHED
}

Waken, a new brand focused on mouthcare, has launched four vegan-friendly mouthwashes with an accompanying 'chic sipping cup'.

Presented in beautiful eco-friendly aluminium bottles and using natural mints and other botanical extracts, Waken's recipes have been crafted with your wellbeing at their heart, to give you fresh breath while being kind to your teeth and gums. The gentle alcohol-free formulas do not contain artificial colours or synthetic flavours. They do contain sodium fluoride to help prevent cavities.

Waken mouthwashes come in four flavours in $500 \mathrm{ml}$ bottles: Waken PepperMint, containing a blend of 'Black Mitcham' peppermint and other botanical extracts to elevate your senses; Waken SpearMint, slightly sweeter than peppermint with a blend of eucalyptus for a gentle, fragrant note; Waken LemonMint, a combination of Black Mitcham peppermint and Sicilian lemons to give you a citrusy boost; and Waken AniseedMint, with spicy notes of aniseed and clove enhancing the Black Mitcham peppermint with a warmer, earthy flavour. Waken mouthwashes cost $£ 8$ and the stainless steel MouthwashCup costs $£ 4$.

Waken mouthwashes are now available in Boots and Sainsbury's nationwide, or visit www.wakencare.com.

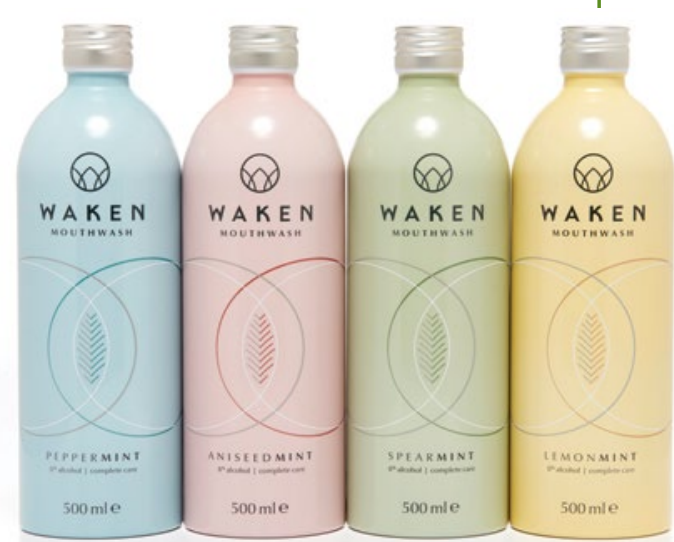

